\title{
Engaging, Data-based, Visual Approach to Explaining Concrete
}

\section{Prof. Jinwoo An, University of Mount Union}

Dr. Jin Woo An joined the University of Mount Union as an Assistant Professor in the Department of Engineering (Civil Engineering) in 2019. He received his Ph.D. in Civil Engineering from the University of Central Florida in 2015. Dr. An is an experienced and energetic educator and researcher. He believes teaching and research go hand in hand. He worked at a structural engineering company as an assistant engineer to finish a structural and mechanical design of a multipurpose building with 29 floors (Macroscale). For his dissertation, he conducted a research on the mechanical and structural performance of cement composite materials, which incorporated sustainable materials (Meso-scale). During his postdoctoral career, he deeply explored the effects of Micro- and Nano-materials as additives in cement composite materials (Micro- and Nano-scale).

\section{Mr. Alan M. Hunter, University of Central Florida}

I am a student at the University of Central Florida, with educational background in Biology, Chemistry, Physics, and Psychology, as well as study in Education, Philosophy, History, and Literature.

Dr. Xi Wang P.E., University of Mount Union

Prof. Boo Hyun Nam, University of Central Florida

Dr. Yong Je Kim, University of Central Florida

Dr. Byoung Hooi Cho, University of Central Florida 


\title{
Engaging, Data-based, Visual Approach to Explaining Concrete
}

\begin{abstract}
Concrete is the most widely used material in the world. The importance of understanding concrete as it pertains to Civil Engineering cannot be emphasized enough. Despite its overwhelming importance, students commonly go only skin-deep into comprehending concrete in the typical undergraduate construction materials class. Traditional course materials tend to be mostly text-based, as opposed to being more imagebased. The visual materials available to generation Z (Gen Z) students on the internet, social media, and other common technological platforms make them very comfortable with images and visual learning. Laptops and cell phones are constant sources of distractions, especially if course materials are largely textbased. In order to ensure that a solid understanding of concrete is achieved, course material should be more Gen Z-friendly. Due to advances in image processing and optical technology, instructors can provide visualized and example-based course materials to explain concrete now more than ever before.

This study presents a visual, data-based, and engaging approach to teaching concrete. This study introduces visuals of (1) crystals of clinker, (2) hydrates growing around cement, (3) microstructures of hydrates (hydration products), (4) Interfacial Transition Zone (ITZ), (5) supplementary cementing materials (SCM). Based on students' initial feedback, these visual and engaging course materials should enhance student engagement in the class.

It should be noted that this study is meant to be supplementary course material, and not replacement of either textbook materials or other primary teaching methodologies.

\section{Introduction}

\section{Motivation}

There are many textbooks [1-5] containing cement and concrete information. As we all know, concrete is the most widely used material in the world. The importance of understanding concrete as it pertains to Civil Engineering cannot be emphasized enough. Despite its overwhelming importance, students commonly go only skin-deep into comprehending concrete in the typical undergraduate construction materials class. Traditional course materials tend to be mostly text-based, as opposed to being more image-based. The visual materials available to generation $\mathrm{Z}$ (Gen $\mathrm{Z}$ ) students on the internet, social media, and other common technological platforms make them very comfortable with images and visual learning. Laptops and cell phones are constant sources of distractions, especially if course materials are largely text-based. In order to ensure that a solid understanding of concrete is achieved, course material should be more Gen Z-friendly. Due to advances in image processing and optical technology, instructors can provide visualized and example-based course materials to explain concrete now more than ever before. In this article, several major textbooks related to construction materials were reviewed to check the utilization of visualized and example-based course materials. And, useful scanning electron microscope (SEM) images are presented.
\end{abstract}

\section{Literature Review}

Five major textbooks [1-5] regarding construction materials were chosen to review the content of construction materials, especially cement and concrete. These five major textbook publishers are Cengage Learning, McGraw-Hill Education, Pearson Higher Education, Wiley and Taylor \& Francis Group. 
Cengage Learning published "Civil Engineering Materials, $1^{\text {st }}$ edition" in 2017 [1]. The authors are Nagaratnam Sivakugan, Carthigesu T. Gnanendran, Rabin Tuladhar, and M. Bobby Kannan. Civil Engineering Materials is composed of 13 chapters. This textbook introduces cement and concrete in chapter 8. It covers constituents of concrete, different stages of concrete, properties of fresh and harden concrete and concrete mix design. This content conveys the general ideas regarding cement and concrete. However, the images presented in the textbook leaves something to be desired. For example, the textbook shows clinker which is a nodular material produced in the kilning stage of cement production. And, it also mentions that this clinker consists of various calcium silicates such as alite, belite, aluminate and ferrite, etc. Nevertheless, it would be more helpful to understand those calcium silicates if the textbook would show crystalline structures of alite, belite, aluminate and ferrite in micro scale. Obtaining visual images of microstructures was limited in former days. Due to advances in image processing and optical technology, however, publishers and instructors can provide visualizations of concrete now more than ever before. This article compares macro size clinker and micro-structures of clinker which are alite, belite, aluminate and ferrite to help student understand calcium silicates.

Pearson Higher Education published "Materials for Civil and Construction Engineers, 4th Edition" in 2016 [2]. The authors are Michael S. Mamlouk and John P. Zaniewski. Materials for Civil and Construction Engineers is composed of 11 chapters. It introduces Portland cement (PC) and PC concrete in Chapter 6 and 7, respectively. The textbook adequately conveys Portland cement from chemical composition of PC to properties of hydrated cement. However, this textbook also leaves something to be desired. For instance, when the textbook explains the development of micro-structure in cement paste, it portrays the microstructures with a rough drawing. If the textbook shows the real micro-structures (which are hydration products of PC) in cement paste, students can more easily understand the content. This article presents scanning electron microscope (SEM) images of cement hydration as visual and image-based examples.

McGraw-Hill Education published "Concrete: Microstructure, Properties, and Materials, 3rd Edition" in 2014 [3]. The author is Kumar Monteiro. This textbook is composed of 14 chapters. Since this textbook is written mainly for concrete material, each chapter adequately conveys concepts and definitions of cement and concrete and even some SEM images of micro-structures are presented in the book. Nevertheless, this textbook is still text-based. For example, most of hydration products such as calcium silicate hydrate (known as CSH), calcium hydroxide (known as portlandite), calcium sulfoaluminates (known as ettringite) are described with words. If more SEM images of these hydration products are presented in the textbook, it would be very helpful for students to understand these hydration products well. This article introduces SEM images of CSH, portlandite and ettringite. In addition, another important subject in concrete which is interfacial transition zone (ITZ) in concrete is introduced in this textbook with some diagrammatic representation of ITZ. This article also presents SEM images of ITZ.

Taylor \& Francis Group published "Construction Materials, Their Nature and Behavior, 5th edition" in 2017 [4]. This textbook is edited by Marios Soutsos and Peter Domone. This textbook is composed of 58 chapters. Concrete is introduced and conveyed from chapter 13 (Portland cement) to chapter 26 (Recycling of concrete). This textbook covers a range of topics related to concrete. For example, chapter 25 introduces supplementary cementing materials (SCMs) such as coal fly ash, silica fume and ground granulated blast furnace slag (GGBFS). It is important to explain the chemical compositions of these SCMs. With SEM images of these SCMs, however, not only chemical properties of SCMs but also physical properties of SCMs such as size, shape, surface texture for those supplement cementitious materials can be explained and compared. This article presents SEM images of coal fly ash, silica fume and ultra-fine fly ash.

Wiley published "Fundamentals of Building Construction: Materials and Methods, 7th Edition" in 2019 [5]. The authors are Edward Allen and Joseph Iano. This textbook is composed of 24 chapters. It introduces 
cement and concrete materials in chapter 13. In chapter 13, this textbook more focuses on concrete construction which is an application of concrete rather than cement and concrete materials themselves.

\section{Improving Students Understanding of Portland Cement, Cement Hydration and Concrete}

\section{Micro-Structure of Clinker and Portland cement}

It is a well known fact that Portland cement can be manufactured either by wet or dry process. Even though the process of feeding raw materials (such as limestone, clay and chalk, etc) to a rotary kiln is different for both processes (wet and dry process), at the end of grinding the raw materials, both processes produce clinker which is the final product of the kilning stage of cement production. "Civil Engineering Materials, $1^{\text {st }}$ edition" [1] which was published by Cengage Learning in 2017 introduces the picture of dry clinker as well as the chemical composition of it. As described in the textbook, clinker consists of various calcium silicates such as alite, belite, aluminate and ferrite, etc. Even though the textbook presents the picture of dry clinker (Figure 1a), it would be more helpful to show crystalline structures of alite, belite, aluminate and ferrite in micro scale. In addition, the textbook published by Cengage only provides a picture of anhydrous Portland cement in figure 1b. The SEM image of Portland cement could be beneficial for students.

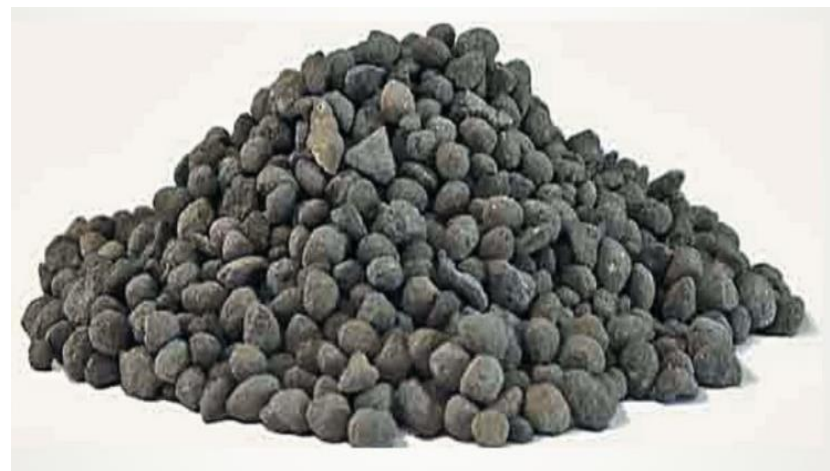

(a)

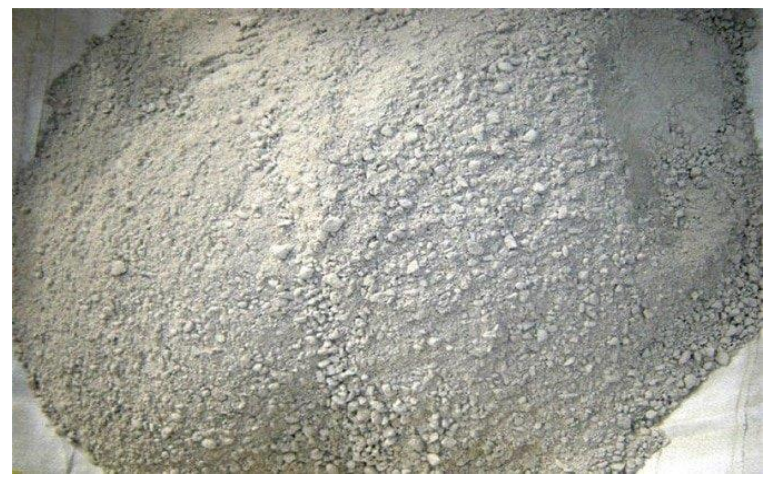

(b)

Figure 1: 1. Pictures of (a) dry clinker and (b) Portland cement [1]

Figure 2a shows SEM images of alite, belite, aluminate and ferrite in clinker [6]. With advances in image processing and optical technology, we can provide students visualization of the micro-structures of these crystal structures. Alite and belite are more active ingredients of cement compared to other ingredients to produce strength of concrete. In general, clinker contains $72 \%$ alite, $9 \%$ belite, $7 \%$ aluminate, $10 \%$ ferrite and $2 \%$ others. Figure $2 \mathrm{~b}$ shows SEM image of Portland cement [7]. Portland cement, we know, has irregular and rough surfaces. Depending on the shape and size of these particles, the workability of concrete can be either increased or decreased. 


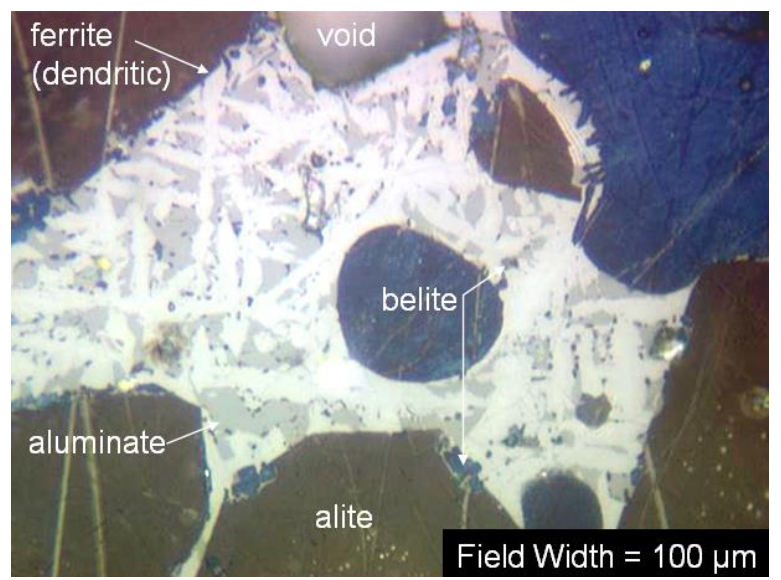

(a)

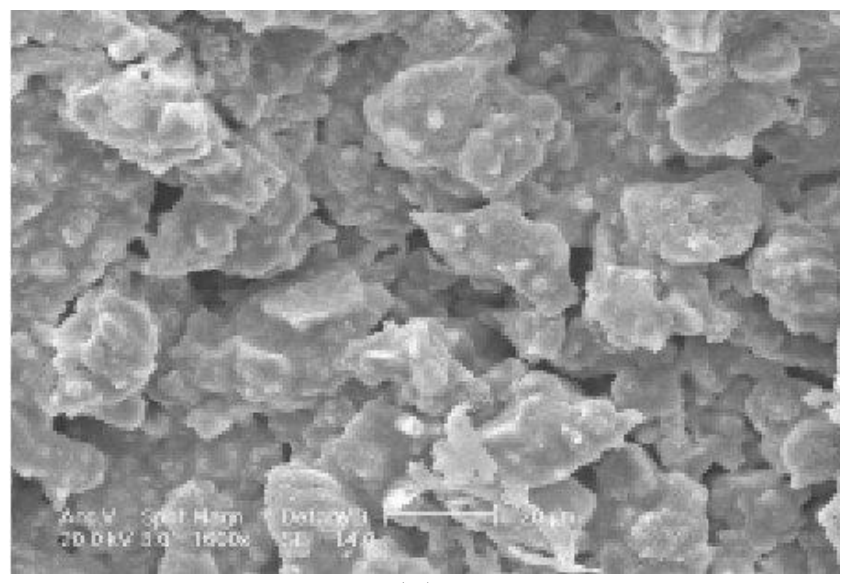

(b)

Figure 2: SEM Images of (a) alite, belite, aluminate and ferrite [6], and (b) Portland cement [7]

\section{Development of micro-structure during cement hydration}

It is crucial to understand the sequential development of micro-structures in cement paste during hydration. Civil Engineering Materials ( $1^{\text {st }}$ edition) and Materials for Civil and Construction Engineers (4th Edition), published by Cengage and Pearson respectively, introduce the structure development in cement paste during cement hydration with drawn figures [1,2]. Figure 3 shows the sequential development of micro-structures in cement. Figure 3 a describes the process, which begins right after water is added to Portland cement. Figure $3 \mathrm{~b}$ shows the growth of hydration products from the cement particle. Figure $3 \mathrm{~d}$ portrays the development of CSH phase from the cement grain. Finally, figure $3 \mathrm{~d}$ describes the increment of hydration products including $\mathrm{CSH}$, portlandite and ettringite. As it is known, cement paste gains strength as hydration products increase. Although these drawn figures can roughly describe the development of micro-structures during cement hydration, it would be much better to use SEM images to explain the sequential development of micro-structures in cement paste during hydration

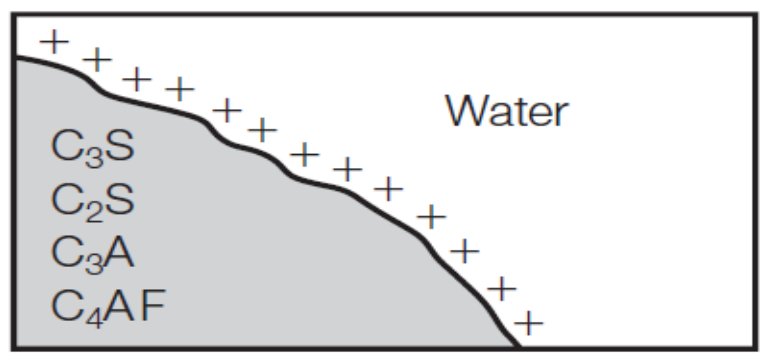

(a)

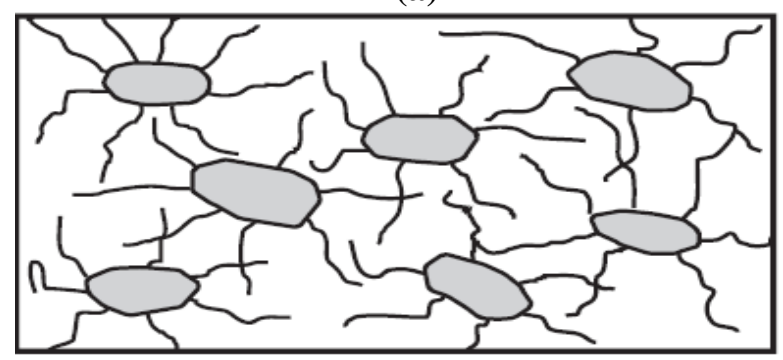

(c)

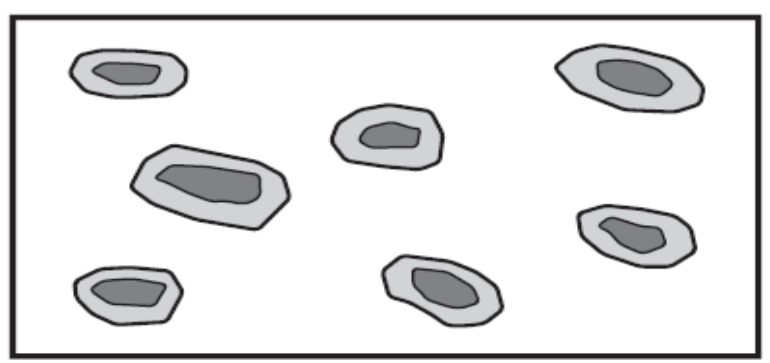

(b)

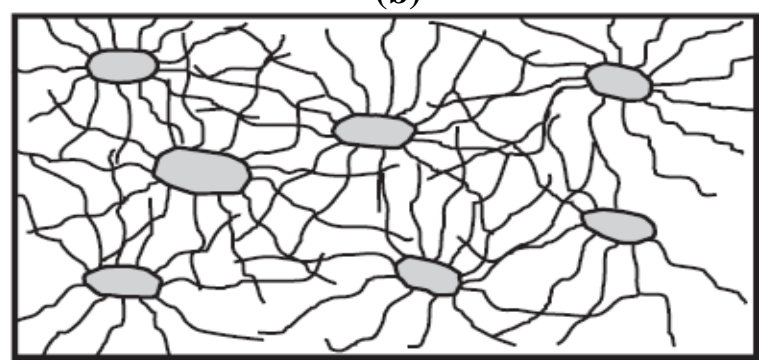

(d)

Figure 3: The sequential development of structure in the cement [2] 
L. Nicoleau and A. Nonat published journal paper which is "A new view on the kinetics of tricalcium silicate hydration" to explain the sequential development of micro-structure in cement paste during hydration with SEM images [8]. Figure 4 describes the sequential development of micro-structure in cement paste during hydration with SEM images. There are four stages of cement hydration. Those four stages are initial hydrolysis (stage 1), induction period (stage 2), acceleration period (stage 3 ) and deceleration period (stage 4).

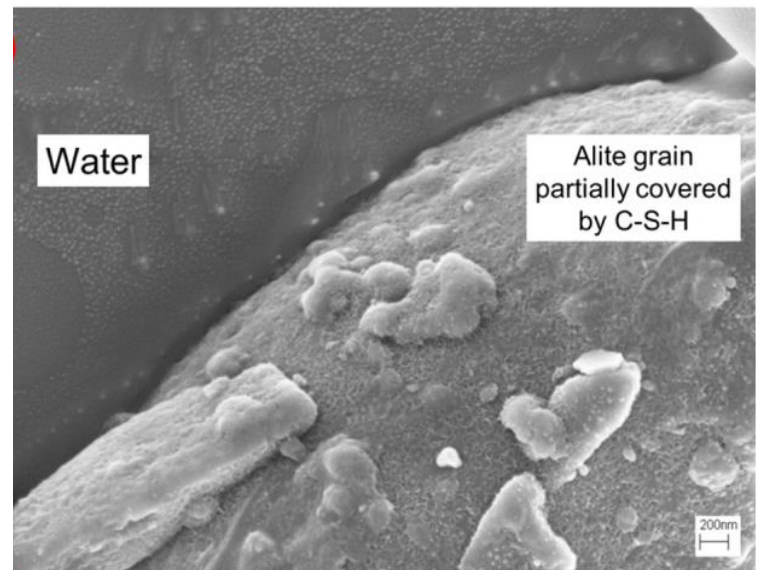

(a)

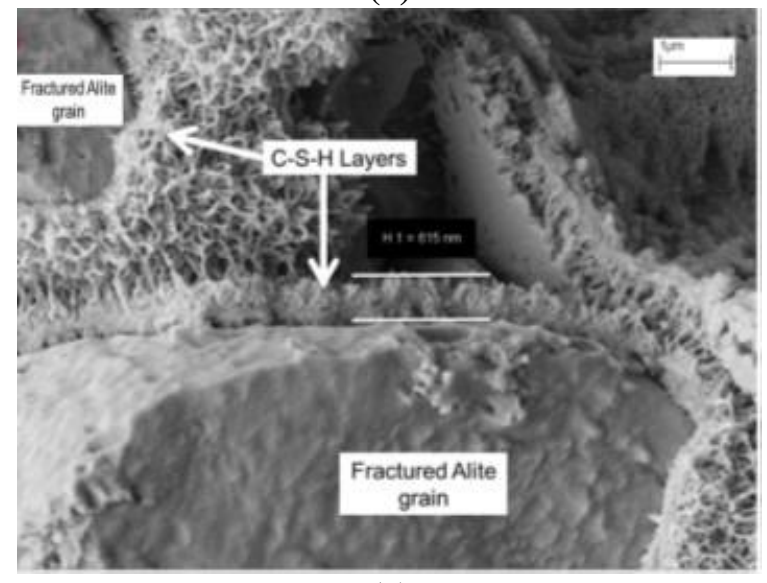

(c)

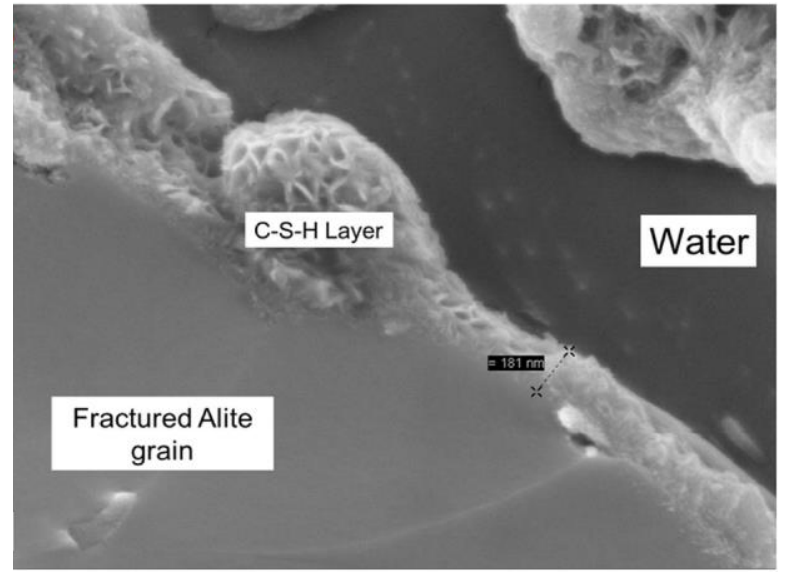

(b)

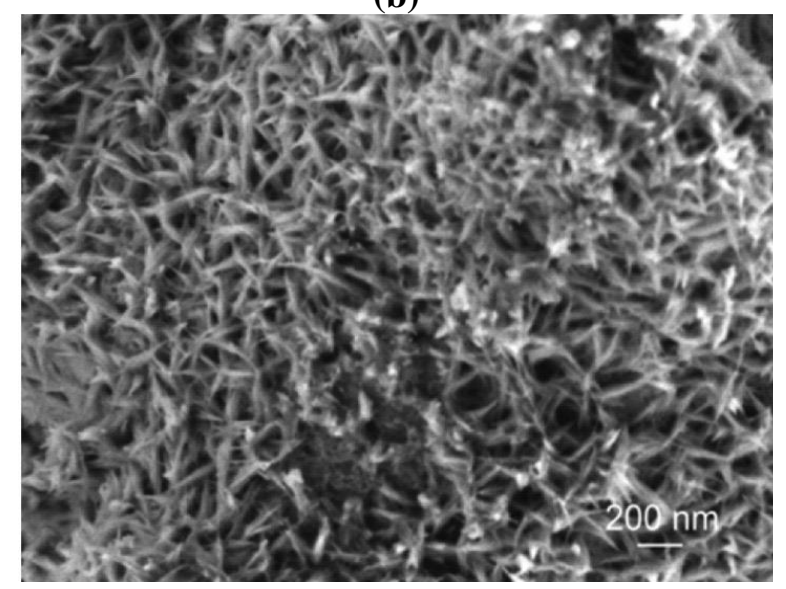

(d)

Figure 4: SEM Images of cement hydration with time [8]

Stage 1 is the initial hydrolysis. During this first stage, cement grains contact water. And, calcium ions and hydroxyl are dissolved in water. At the end of stage 1, early CSH forms on the surface of cement grain. Stage 1 takes a couple minutes. The initial hydrolysis is captured in figure $4 \mathrm{a}$.

Stage 2 is the induction period. During this stage, hydrolysis slows down and the dissolution of tricalcium silicate $\left(\mathrm{C}_{3} \mathrm{~S}\right)$ which is a major chemical component of Portland cement also slows down. Even though early $\mathrm{CSH}$ forms on the surface of cement grain, cement paste still remains fluid. Stage 2 takes 2 to 4 hours. The induction period is described in figure $4 \mathrm{~b}$.

Stage 3 is the acceleration period. Calcium hydroxide which is known as portlandite crystallizes from the solution. CSH develops further at the surface of $\mathrm{C}_{3} \mathrm{~S}$ grain. The final setting, which is the time taken by cement to gain its entire strength occurs, and hardening, in which a process of crystallization begins. Stage 3 takes 5 to 8 hours. The acceleration period is captured in figure $4 \mathrm{c}$. 
Stage 4 is the deceleration period. CSH layer thickens and interconnects each other. Barrier forms around $\mathrm{C}_{3} \mathrm{~S}$. Mass transport though CSH determines rate of reaction. And, hydration becomes diffusion controlled. Stage 4 takes from 10 hours to a couple of days. The deceleration period is presented in figure $4 \mathrm{~d}$.

\section{Hydration products of Portland cement}

Through the sequential development of micro-structure during cement hydration, several different types of hydration products are formed. One of the major hydration products is $\mathrm{CSH}$ which is responsible for the strength of concrete. $\mathrm{CSH}$ has amorphous morphology and is clearly shown in figure 5a and figure $5 \mathrm{~b}$. In figure 5a, CSH bridges the gap between anhydrous cement grains. In figure 5b, area 1 and area 2 shows the amorphous shape of $\mathrm{CSH}$. Another hydration product is ettringite. Ettringite is a normal by-product of early cement hydration. Ettringite has a needle-like shape and can be seen from points 3 and 4 of figure $5 \mathrm{~b}$. Even though ettringite has strength, that strength is relatively small compared to CSH. Therefore, engineers try to reduce or limit the development of this by-product. The other hydration product is portlandite. Cement hydration produces a large amount of portlandite which constitutes about $20-30 \%$ of the hydration product mass of cement paste. It appears in the form of large hexagonal crystals. Even though it possesses a high volume in cement paste, it has a relatively minor impact on the strength of concrete. Portlandite can be found in figure $5 \mathrm{~b}$ at point 5 .

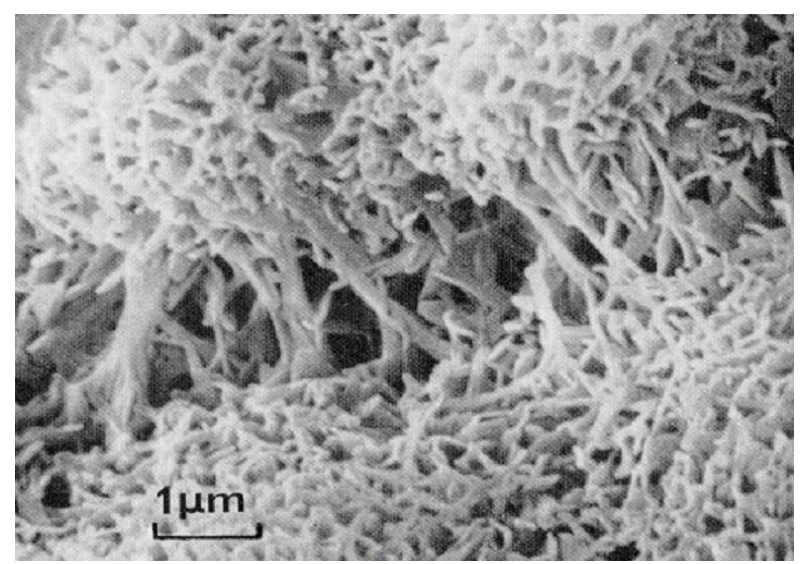

(a)

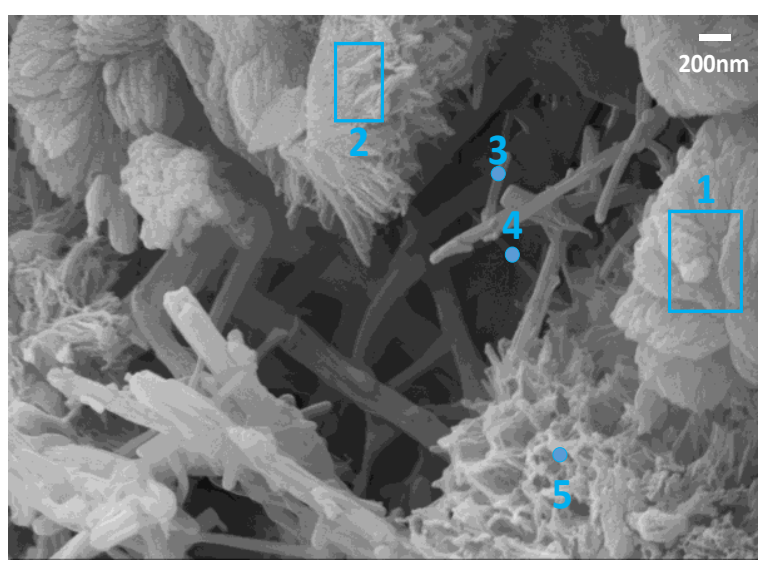

(b)

Figure 5: SEM images of (a) CSH and (b) CSH $(1,2)$, ettringite $(3,4)$, and portlandite (5) [9]

\section{Interfacial Transition Zone (ITZ) in concrete}

Interfacial transition zone is a layer which contains relatively larger crystals between cement and aggregate. Depending on the water to cement ratio, the types of aggregate and cement as well as the size and shape of crystalline structures near aggregates can be affected and changed. These larger crystals may form a more porous framework than in the general cement paste, mortar or concrete matrix. This ITZ in concrete is introduced in "Concrete: Microstructure, Properties, and Materials [3]" with some diagrammatic representations of ITZ (see Figure 6). 


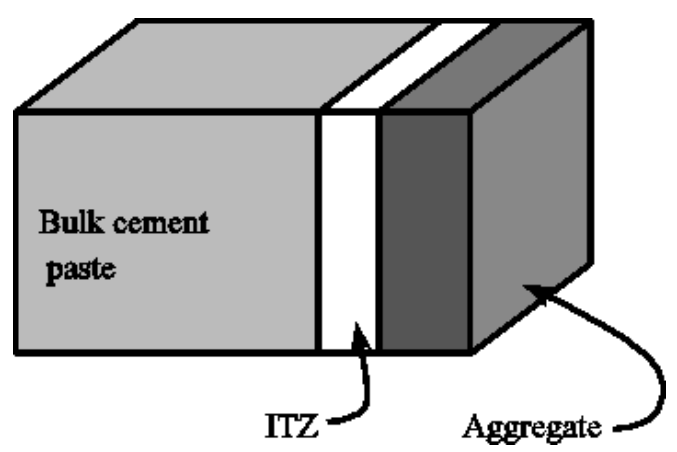

(a)

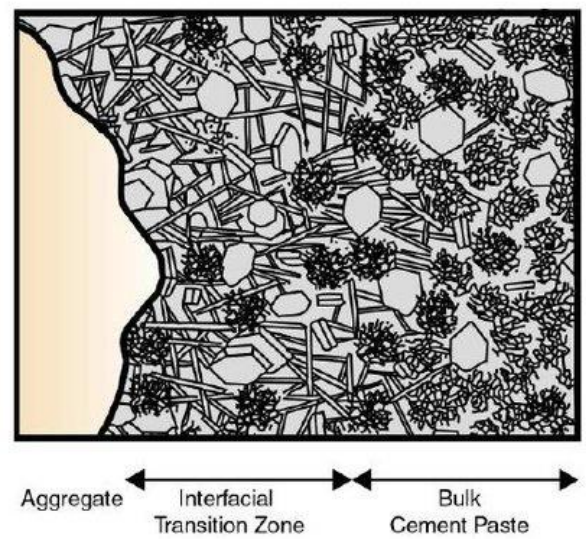

(b)

Figure 6: Diagrammatic representation of ITZ in concrete [3]

With advances in image processing and optical technology, some researchers were able to capture visualized SEM image of ITZ and even determine the thickness of ITZ in concrete. Figure 7a shows a backscatter SEM image of ITZ in concrete. In figure 7a, the interface between granite (coarse aggregate) and bulk cement paste, and micropores near the interface are clearly shown in SEM image. The thickness of ITZ can be determined with a line scanning of energy-dispersive X-ray (also known as EDX). Figure 7b shows the direction of the line scanning of EDX. Figure 7c shows the result of the line scanning of EDX. In figure $7 \mathrm{c}$, there is a section which has high calcium (Ca) content and very low silicon ( $\mathrm{Si}$ ) content. This trend may indicate a large amount of portlandite $\left(\mathrm{Ca}(\mathrm{OH})_{2}\right)$ in the ITZ. Within that section, moreover, The $\mathrm{Ca}$ and $\mathrm{Si}$ content suddenly decreased, while the magnesium $(\mathrm{Mg})$ content significantly increased. This significant increment of magnesium indicates the beginning of another coarse aggregate (dolomite).

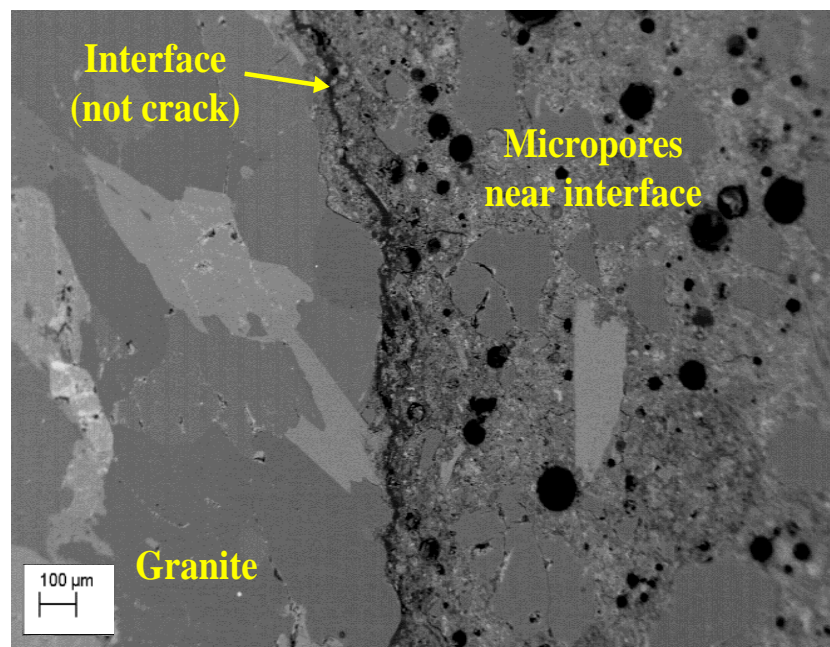

(a)

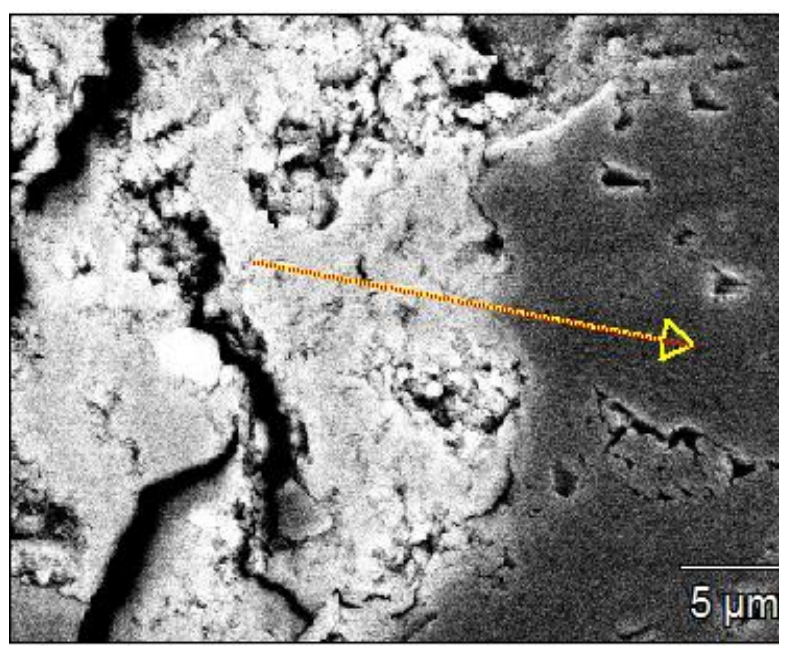

(b) 


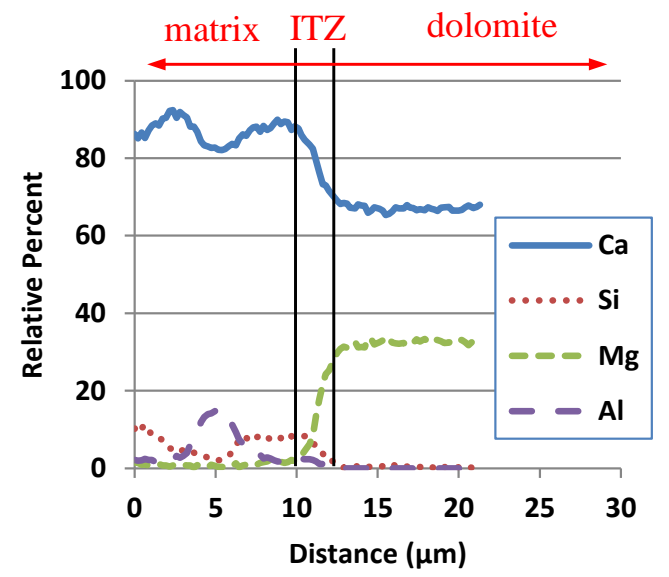

(c)

Figure 7: SEM images of (a) ITZ zone, (b) direction of (c) relative percent of chemical component [10]

\section{Supplementary Cementing Materials (SCM)}

The SEM image of various supplementary cementing materials such as coal fly ash, silica fume and ultrafine fly ash are presented in Figure 8. For comparison purposes, the figure also presents the SEM images of Portland cement. In the figure, the differences in size, shape, and surface texture for those supplemental cementitious materials and Portland cement are clearly compared. It is shown that coal fly ash and ultrafine fly ash exhibit more round-shape particles. On the other hand, Portland cement and silica fume have more angular and cylindrical particles on sintered clusters with highly crystalline phases. In addition, Portland cement and silica fume have irregular and rough surfaces compared to other two fly ashes from the SEM images. Irregular and rough surfaces can cause a reduction in the workability of concrete. In other words, the addition of coal fly ash can cause an increase in the workability of concrete.

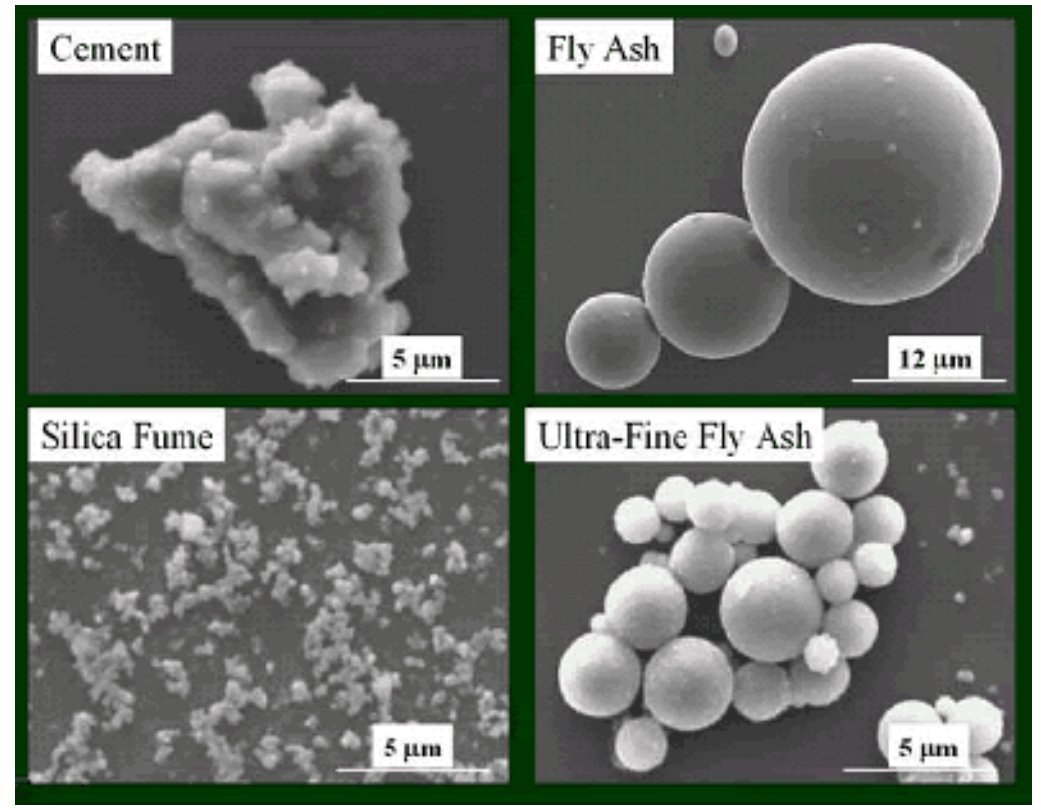

Figure 8: SEM images of Portland cement and supplementary cementing materials [11] 


\section{$\underline{\text { Assessment }}$}

The methods and examples shown in this article were implemented in Construction Material and Structural Analysis classes taught by co-authors of this article at the University of Mount Union. A questionnaire was distributed to students at the end of the lecture in order to gauge how receptive students were to the engaging, data-based, visual approach presented in this article. The responses are based on a class presentation that included the examples in this article. 30 students filled out the questionnaire. A summary of the questionnaire and raw results can be found below:

1. Importance of visualizing construction material

2. Importance of being introduced to cement hydration concepts through visual examples

3. Importance of understanding hydration products with SEM images

4. Importance of understanding interfacial transition zone (ITZ) with SEM images

5. Importance of understanding Supplementary Cementing Materials (SCM) with SEM images

6. Importance of traditional presentations for learning concrete material

7. Importance of PowerPoint presentations for learning concrete material

8. Visual presentation of cement and concrete helped me better understand concrete

9. Importance of learning concrete material through textbook reading

10. Would you like to learn other construction materials with visualized course material?

The questionnaire utilized a scale to determine the students' opinions regarding the importance of the materials and methods comprising the learning experience consisted of five options: Very important, Important, Moderately important, Slightly important, and Not important. Regarding the students' opinions regarding the effectiveness of the various materials presented or learning methods, the scale ranged from: Strongly agree, Agree, Neutral, Disagree, and Strongly disagree.

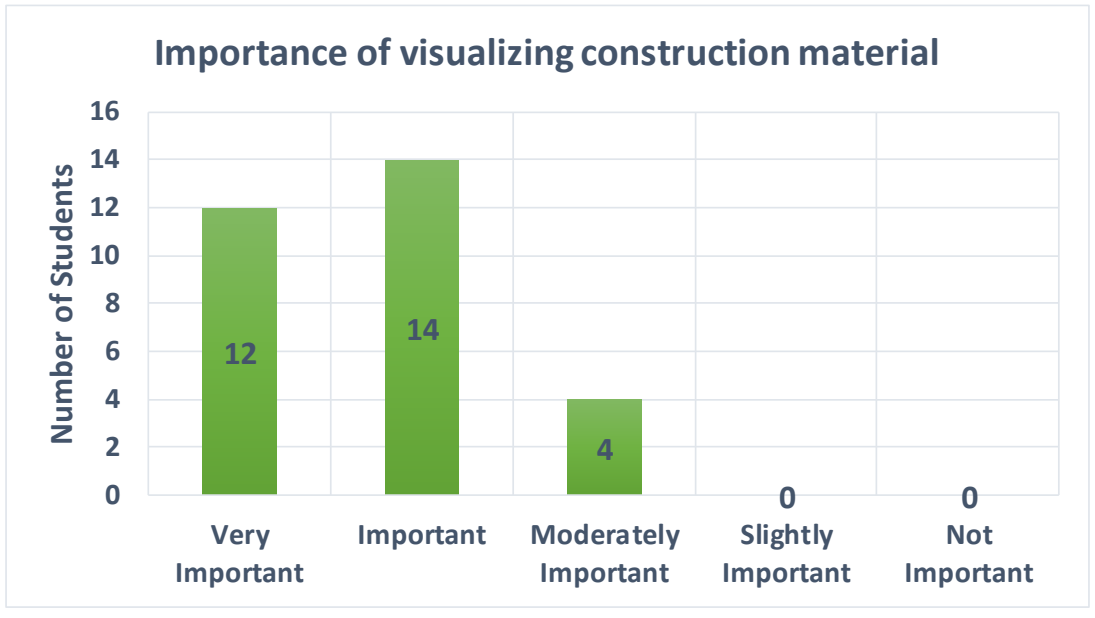

Figure 9: Student feedback on importance of visualizing construction material 


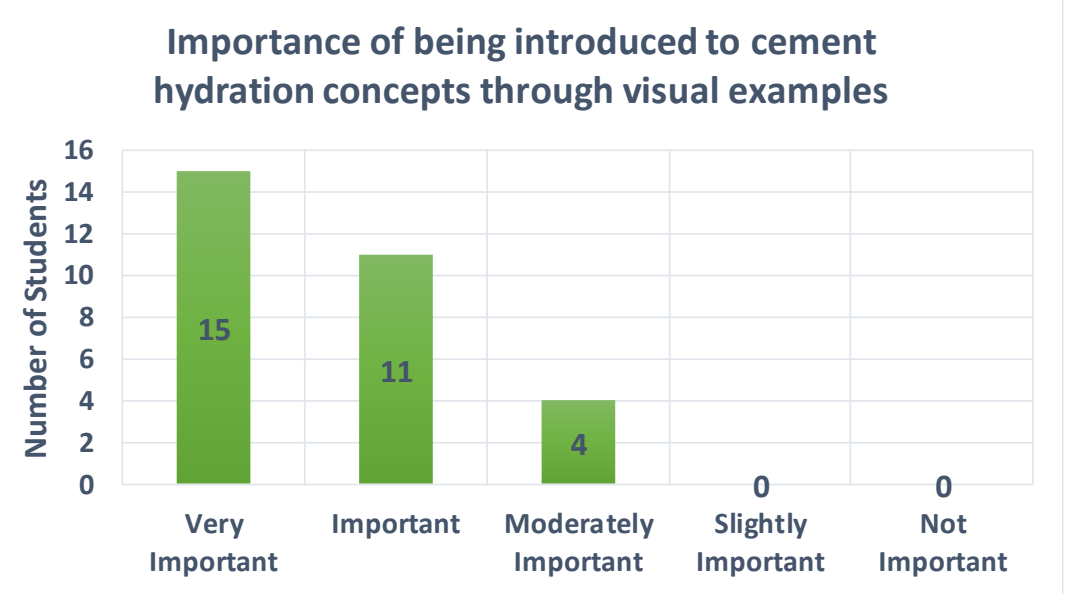

Figure 10: Student feedback on importance of being introduced to cement hydration concepts through visual examples

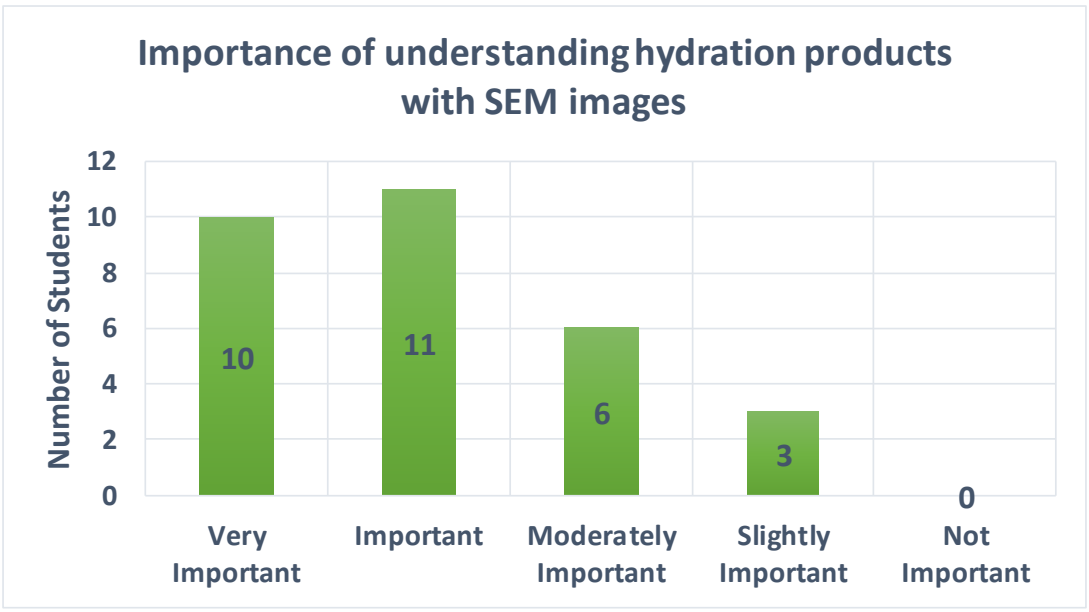

Figure 11: Student feedback on importance of understanding hydration products with SEM images

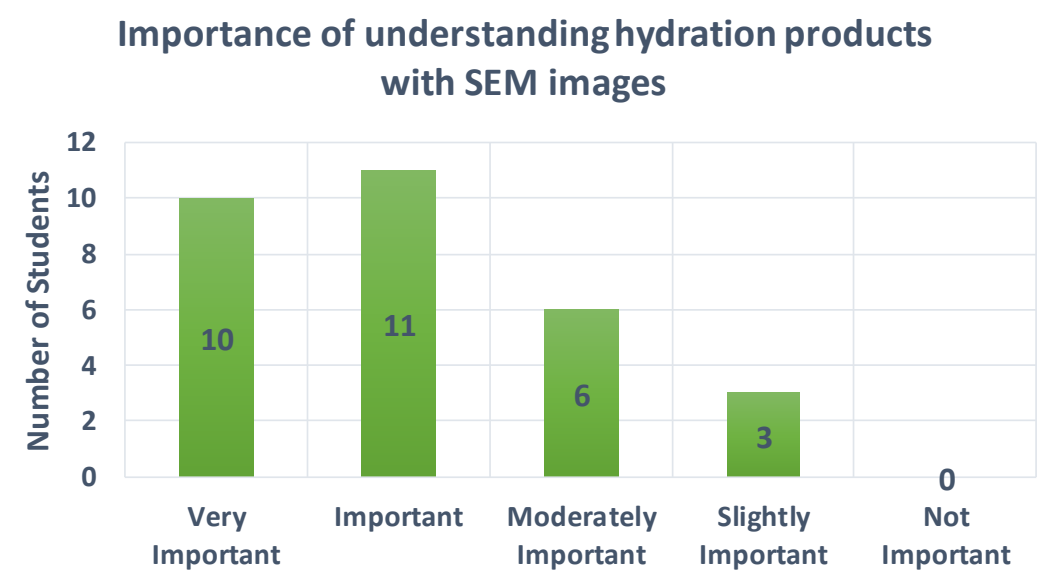

Figure 12: Student feedback on importance of understanding interfacial transition zone (ITZ) with SEM images 


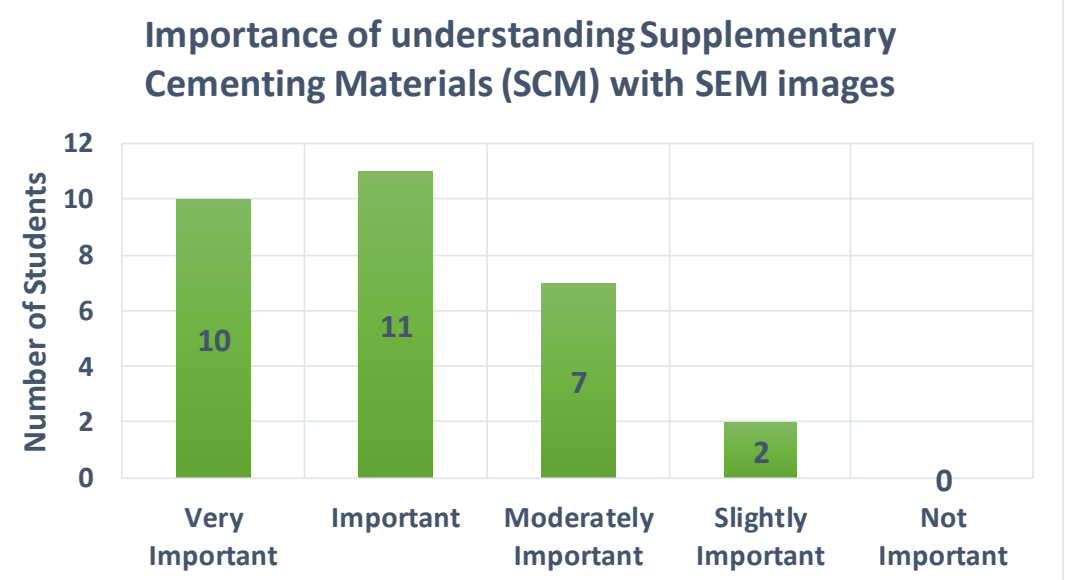

Figure 13: Student feedback on importance of understanding Supplementary Cementing Materials (SCM) with SEM images

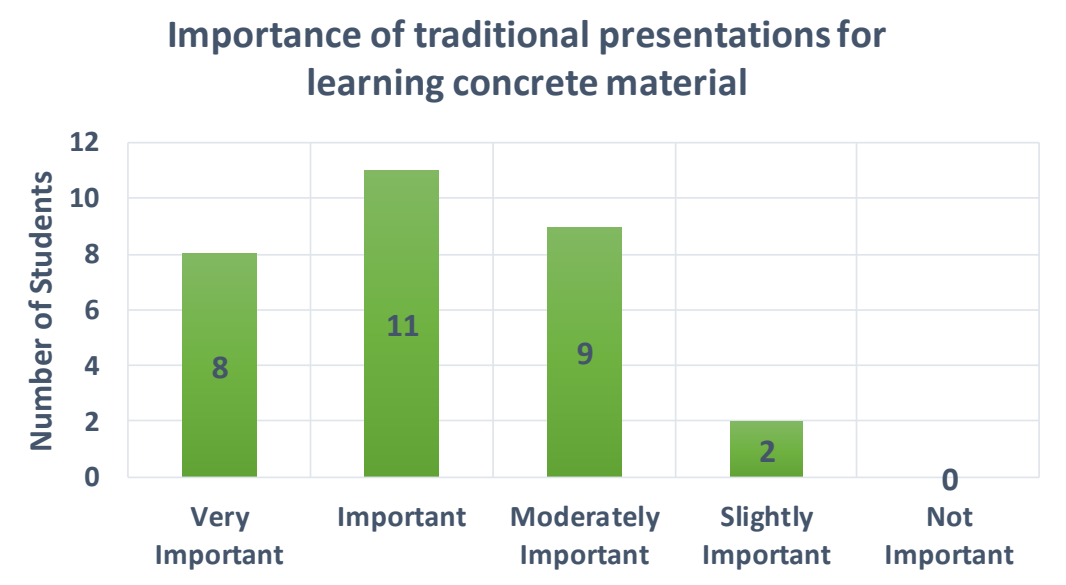

Figure 14: Student feedback on importance of traditional presentations for learning concrete material

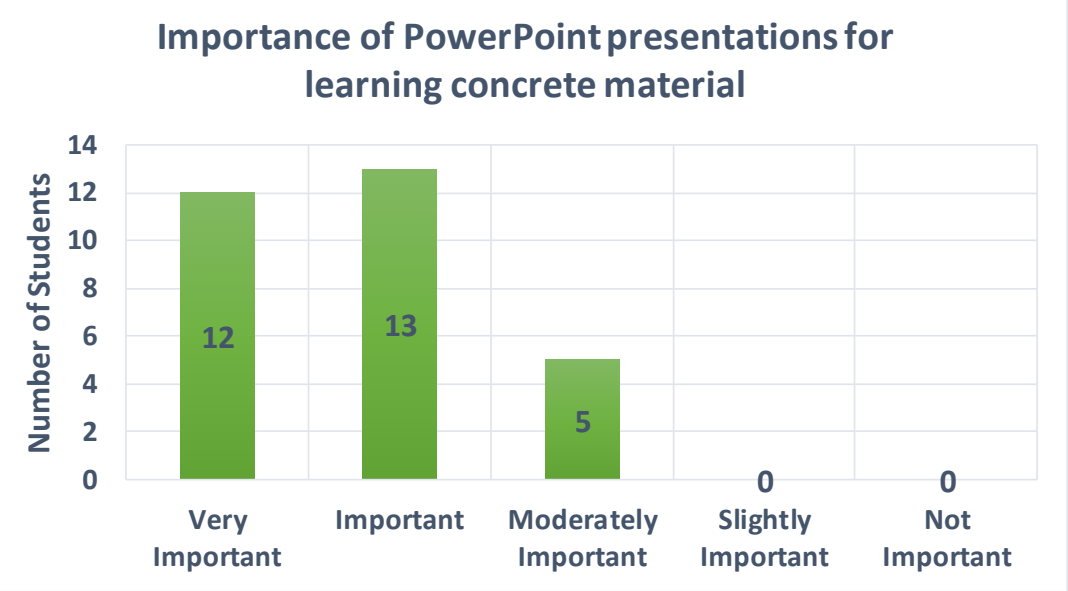

Figure 15: Student feedback on importance of PowerPoint presentations for learning concrete material 


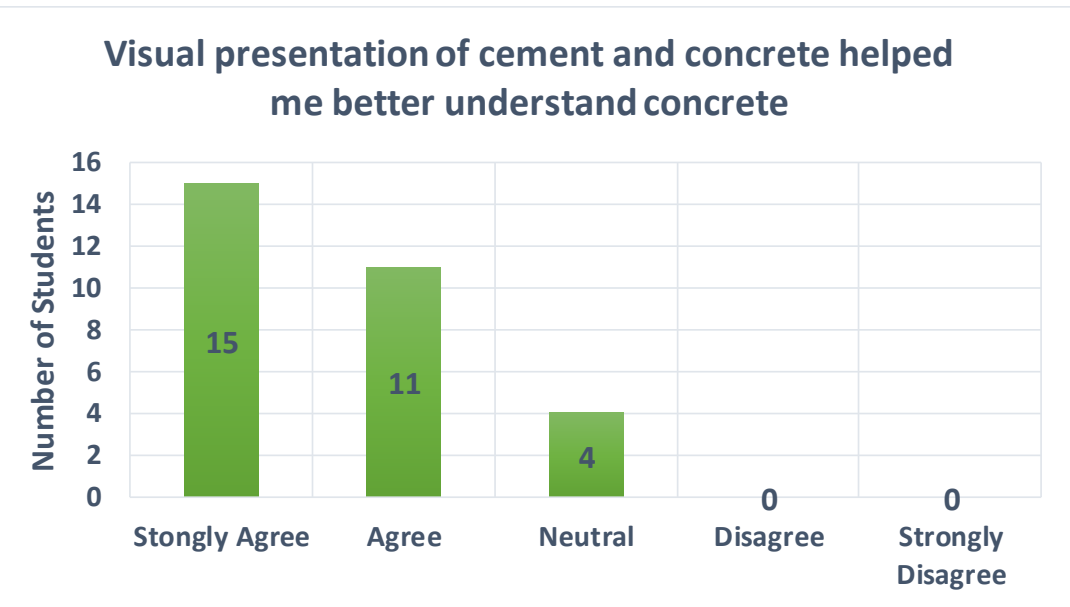

Figure 16: Student feedback on visual presentation of cement and concrete helped me better understand concrete

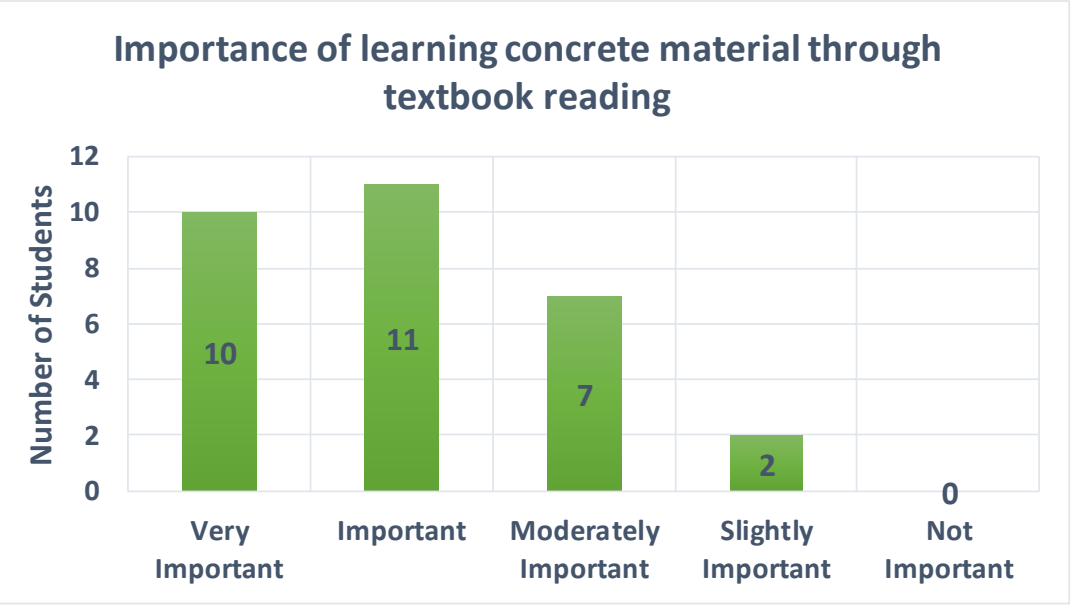

Figure 17: Student feedback on importance of learning concrete material through textbook reading

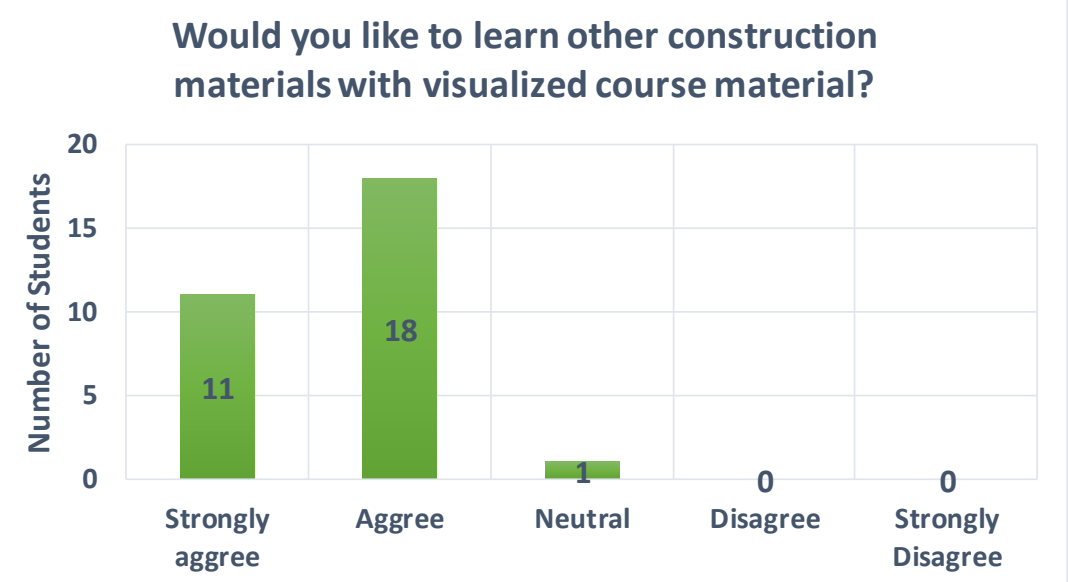

Figure 18: Student feedback on would you like to learn other construction materials with visualized course material? 
The response from the students strongly indicated the importance of being exposed to visual examples to aid in the learning and understanding of concrete materials. The results show that regarding the "Importance of being introduced to cement hydration concepts through visual examples," 50\% responded with "very important" and an additional 37\% responded with "important". Of all the questions regarding the importance of learning concrete materials, no student marked "slightly important" or "not important". Regarding the "Visual presentation of cement and concrete helped me better understand concrete, 50\% responded "very important," and an additional 37\% responded "important." Only 10\% of students responded "moderately important" and none selected that the visual presentation was not important.

Students subjectively found that visual presentations helped them understand concrete. Responding to the questions, "visual presentation of cement and concrete helped me better understand concrete," and, "would you like to learn other construction materials with visualized course material?" most students either agreed or strongly agreed. Few felt neutral and no students disagreed or strongly disagreed. Based on the results, many students strongly felt that they learn better with visualized and example-based course materials.

\section{Conclusion and recommendation}

The present article indicates more work is needed to collect additional data regarding the effectiveness of utilizing these learning methods. Future data and research-based examples are being developed and produced as a follow-up to these lecture models. For example, data and research-based examples, including EDX line scanning, was omitted. Research-based explanations would be needed, which would perhaps constitute a further development of the learning process regarding concrete and cementitious materials. Other important construction topics, which are deemed integral to understanding major civil engineering principles and which cause students to struggle, are being expanded to utilize the advanced image and visualization techniques of this teaching method.

\section{$\underline{\text { References }}$}

[1] C. T. G. Nagaratnam Sivakugan, Rabin Tuladhar, and M. Bobby Kannan, Civil Engineering Materials, 1 st edition ed. Cengage Learning, 2017.

[2] M. S. M. a. J. P. Zaniewski, Materials for Civil and Construction Engineers, 4th Edition ed. Pearson Higher Education 2016.

[3] K. Monteiro, Concrete: Microstructure, Properties, and Materials, 3rd Edition ed. McGraw-Hill Education, 2014.

[4] M. S. a. P. Domone, Construction Materials, Their Nature and Behavior, 5th edition ed. Taylor \& Francis Group 2017.

[5] E. A. a. J. Iano, Fundamentals of Building Construction: Materials and Methods, 7th Edition ed. Wiley, 2019.

[6] P. S. a. S. Leigh, "Phase Composition Analysis of the NIST Reference Clinkers by Optical Microscopy and X-ray Powder Diffraction," 2002.

[7] M. G. Oliveira, C. B. Xavier, F. F. Demarco, A. L. Pinheiro, A. T. Costa, and D. H. Pozza, "Comparative chemical study of MTA and Portland cements," (in eng), Braz Dent J, vol. 18, no. 1, pp. 3-7, 2007.

[8] L. Nicoleau and A. Nonat, "A new view on the kinetics of tricalcium silicate hydration," Cement and Concrete Research, vol. 86, pp. 1-11, 2016/08/01/ 2016.

[9] J. An, M. McInnis, W. Chung, and B. H. Nam, "Feasibility of Using Graphene Oxide Nanoflake (GONF) as Additive of Cement Composite," Applied Sciences, vol. 8, no. 3, p. 419, 2018. 
[10] J. An, S. S. Kim, B. H. Nam, and S. A. Durham, "Effect of Aggregate Mineralogy and Concrete Microstructure on Thermal Expansion and Strength Properties of Concrete," Applied Sciences, vol. 7, no. 12, p. 1307, 2017.

[11] J. A. J. K. B. H. Nam, "Investigation on Impacts of Municipal Solid Waste Incineration Bottom Ash on Cement Hydration," ACI Materials Journal, vol. 114, no. 5, pp. 701-711, 2017. 